\title{
Analysis on the Structure of Influencing Factors of Sustainable Supply Chain Implementation of Water Diversion Project
}

\author{
Meng Liu*, Liwei Yang*, Tongsheng Liu\# \\ School of Information and Management Science, Henan Agricultural University, Zhengzhou, China \\ Email: "1tsh2000@163.com
}

How to cite this paper: Liu, M., Yang, L. W., \& Liu, T. S. (2021). Analysis on the Structure of Influencing Factors of Sustainable Supply Chain Implementation of Water Diversion Project. Journal of Geoscience and Environment Protection, 9, 140-150. https://doi.org/10.4236/gep.2021.98009

Received: July 12, 2021

Accepted: August 15, 2021

Published: August 18, 2021

Copyright $\odot 2021$ by author(s) and Scientific Research Publishing Inc. This work is licensed under the Creative Commons Attribution International License (CC BY 4.0).

http://creativecommons.org/licenses/by/4.0/

\begin{abstract}
The systematic analysis of the hierarchical relationship among the factors affecting the sustainable supply chain implementation of water diversion projects has theoretical value and practical significance for the sustainable development of large-scale water diversion projects. Through the investigation of relevant literature, books, web pages, materials, and discussions with relevant experts and scholars, a total of 23 factors influencing the sustainable supply chain implementation of water diversion projects were identified. Then using ISM (Interpretative Structural Modeling Method) to analyze the causality of each factor, a multi-level hierarchical structure model was obtained. The results showed that: 1) The surface-level influencing factors of the sustainable supply chain implementation of the water diversion project mainly included 8 factors such as water-saving awareness and water-saving intensity in the diversion area, water quality, water pollution and other disasters, effective incentive mechanisms, etc., and surface-level influencing factors were directly related to the sustainable supply chain implementation of water diversion projects. 2) The indirect influencing factors of the sustainable supply chain of water diversion projects included 12 factors such as the water quality and quantity guarantee rate of the supply chain, the government's enforcement of laws and regulations, water distribution, ecological compensation, and compensation mechanisms for residents in the water source area. Indirect influencing factor scan acts directly on the direct influencing factors, and intervening in the factors that can be controlled by humans is one of the important ways to improve the sustainable operation of water diversion projects. 3) The fundamental influencing factors for the sustainable supply chain implementation of water diversion projects included three factors: Resettlement
\end{abstract}

*Authors contribute equally.

\#Corresponding author. 
policy, government financial support, and sound laws and regulations. Deep influencing factors had multi-channel influence and controllability, and intervening in them was the main means to improve the sustainable operation of water diversion projects.

\section{Keywords}

Water Diversion Project, Sustainable Supply Chain, Interpretative Structural Modelling Method, Hierarchical Structure Model

\section{Introduction}

Many large-scale water diversion projects have been built in China to solve the shortage of water resources and the uneven distribution of time and space. Such as: "Jiang-Han Water diversion, Luan-Tang Water diversion, Yangze-Taihu Water diversion, South-to-North Water diversion, etc. (Gao et al., 2018; Wang, 2002)." The cross-drainage basin water diversion project sent a large number of clean water resources to the drainage area, injecting strong impetus to the local economic development. More scholars integrate the idea of the supply chain into the related research on the operation and management of water diversion projects. For example, Wang Huimin's team was the first to discuss the feasibility of implementing supply chain management of the water diversion project (Wang et al., 2004). And traditional supply chain mainly focuses on the economic benefits, as many of the water diversion projects are completed and are bubbled into the water, its public welfare nature, engineering has created environmental benefit. Social benefit is gradually caused extensive discussion among scholars. Therefore, implementing the water diversion project considering the economic, environmental, and social benefits fits in with the three principles of "economic, social, and environmental" (Elkington, 1998). It is reasonable and applicable to apply the theories and methods of the sustainable supply chain to the study of water diversion projects.

After Wang Huimin's team proposed the supply chain of the water diversion project and verified its rationality, some experts and scholars did further research and exploration. The research includes the definition of its concept and connotation, the conflict and cooperation among stakeholders, the formation of water price in the supply chain of the water transfer project, eco-compensation, and its social benefits. For example, based on defining the supply chain system of the water transfer project, Chen Zhisong established Stackelberg's game model and the mechanism of shared income with the project's social responsibility as the entry point (Chen, 2013). Then he took the water transfer company and the waterworks in the water transfer project as the research object and studied the profit distribution of the two companies in the case of cooperation and non-cooperation in the way of the game (Lou \& Liu, 2018). In terms of ecological compensation, Guo Ying studied the migration behaviour of migrant house- 
holds in migration and the factors affecting them based on Evolutionary game theory (Guo \& Tai, 2018). With the further combing of relevant literature, he found that scholars combined the actual operation situation of the project and regarded the economic interests of the project subject and stakeholders as the research focus (Chen \& Wang, 2012a, 2012b). However, some water transfer projects' environmental and social benefits are becoming more and more evident as they are put into operation one after another. Obviously, the theory of sustainable supply chain based on the triple bottom line of economic profit, environmental protection, and social responsibility is more suitable for the coordinated management and practice of water diversion projects (Zhang et al., 2019). Among them, Li Warring States has confirmed the rationality of constructing the coordinated management model of the sustainable supply chain of water diversion projects (Li et al., 2021a).

Through the literature review, we find relatively few kinds of literature that study the economic benefit, environmental benefit, and social responsibility of water transfer projects from the perspective of the sustainable supply chain, let alone the research on the implementation and influencing factors of the sustainable supply chain of water transfer project. Based on relevant studies, this paper first constructs the index system of the sustainable supply chain of water diversion projects and the factors affecting it. Using the ISM method, this paper creates the factors affecting the multi-level hierarchical structure model and analyzes the relationship between the elements at different levels. It also provides reference and decision-making support for large-scale water transfer projects' operation and management practice and enriches the relevant theories of the sustainable supply chain of water transfer projects.

\section{ISM Finite Element Method}

\subsection{Method Definition}

Professor Warfel proposed the method of explaining the structural model in the United States (Yang, \& Wang, 2017). This method has been widely used in systems engineering. It is a technical method that can use to divide the hierarchical structure of the system (Zhu et al., 2020). This method will be more complex system is decomposed into several subsystems, and combining the practice of the computer and the system, through the establishment of directed graph and matrix, finally construct the abstract factors in the system of hierarchical structure, identify the surface factor and essential factor in the system, this method can transform vague ideas and views into intuitive structure model. It has a good effect on the problems with many variables and complex relations (Yang \& $\mathrm{Li}$, 2018).

\subsection{Method of ISM Model Construction}

The analysis process of the influencing factors of a sustainable supply chain is based on the implementation of the ISM water diversion project. The figure is referenced from the study of (Zhu et al., 2020) (Figure 1). 


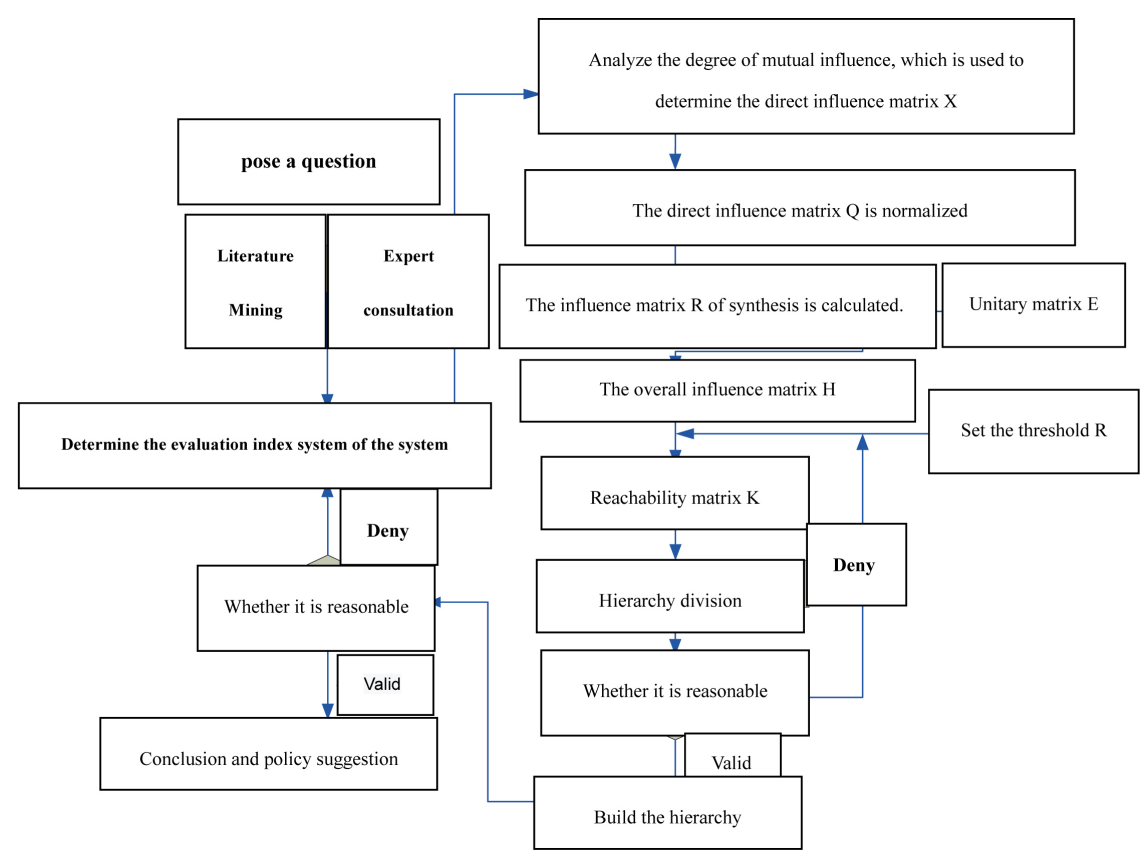

Figure 1. Analysis flow of the influencing factors of the sustainable supply chain based on the implementation of the ISM water diversion project.

The implementation steps based on the ISM model are as follows:

1) Firstly, to determine influencing factors of the sustainable supply chain of water transfer projects, as: $S_{1}, S_{2}, S_{3}, \cdots, S_{n}, S_{i} \in G(i=1,2,3, \cdots, n)$, and " $n$ " is the number of influencing factors, and $G$ is the set of influencing factors.

2) Describe the strength of the effect of factor on $i$ factor $j$ and denote it by $x_{i j}$, and the degree of leverage of the relationship between elements can be measured by the 4-level scale method, and use integer values from 0 to 3 to represent "no impact", "some impact", "strong impact" and "strong impact" respectively.

3) Construct the direct impact matrix $X$. Using the degree of influence among factors as an element and combining the results of several experts, the initial matrix of direct impact is obtained as follows:

$$
X=\left(x_{i j}\right)_{n \times n} .
$$

4) Calculate the normalized influence matrix $Q$. The maximum value of each element in the directly affecting matrix $X$ divided by the sum of its elements in each row is as follows:

$$
Q=\frac{1}{d} \cdot X, d=\max _{1 \leq i \leq n} \sum_{j=1}^{n} x_{i j} .
$$

5) Calculate the integrated impact matrix $R$. Considering the indirect influence between factors and the spread effect caused by the change of one of the factors, we can obtain the following formula from the accumulation of direct and indirect influences:

$$
R=Q+Q^{2}+\cdots+Q^{n}=\sum_{i=1}^{n} Q^{i}
$$


6) Calculate the overall impact matrix. The global influence matrix $H\left(H=\left[h_{i j}\right]_{n \times n}\right)$ is calculated by adding $R$ to the identity matrix $E$, as: $H=R+E$.

7) Determining the reachability matrix. When Reachable matrix $K\left(K=\left[k_{i j}\right]_{n \times n}\right)$ is determined, a threshold value $\lambda$ shall be introduced to process the matrix of overall influence. The formula is as follows:

$$
k_{i j}=\left\{\begin{array}{l}
1, h_{i j} \geq \lambda(i, j=1,2, \cdots, n) \\
0, h_{i j}<\lambda(i, j=1,2, \cdots, n) .
\end{array}\right.
$$

The purpose of setting threshold $\lambda$ is to remove the relationship between the factors with a slight influence degree and simplify the structure of the system. If a larger threshold is used, the correlation between influencing factors will be stronger, and the structure of the system will be simpler and broader, resulting in the difficulty in showing the relationship between influencing factors. If smaller thresholds are used, the relationships between influencing factors will be too complex, and the overall performance will not easily express the system's integrity clearly. In this study, the method of Shu Yang was adopted when selecting the threshold value, and we verified the analysis of the multiple values of the threshold value to obtain the best model of the system structure.

8) Determine reachable set $Y_{i}$ and Antecedent set $P_{i}$, the formula is as follows:

$$
\left\{\begin{array}{l}
Y_{i}=\left\{S_{j} \mid S_{j} \in G, k_{i j}=1\right\}(i, j=1,2, \cdots, n) \\
P_{i}=\left\{S_{i} \mid S_{i} \in G, k_{i j}=1\right\}(i, j=1,2, \cdots, n) .
\end{array}\right.
$$

9) Determine the risk factors of each layer in Genealogical Hierarchy Structure Model $Y_{i}$, the formula is as follows:

$$
Y_{i}=Y_{i} \cap P_{i}(i=1,2, \cdots, n) .
$$

If the above formula can be satisfied, indicating that the antecedents of elements in $P_{i}$ can be found in $Y_{i}$, then $S_{i}$ is the most high-level element, and the $i$ row and $i$ column are removed in the Reachable matrix $K$, and this step is repeated until we can identify all levels. According to the determined elements of different levels, the model of influencing factors of the sustainable supply chain for implementing the water transfer project is constructed.

\section{Construction and Analysis of Hierarchy Structure Based on ISM Influencing Factors}

\subsection{Methods for Calculating ISM}

The sustainable supply chain of the water transfer project involves many nodes, and its successful implementation is due to the influence of many factors. Combined with Li Warring States' identification of the influencing factors of the sustainable supply chain of water transfer project, the influencing factors are divided into four first-level indicators: Society, government, environment, economy, and supply chain, and are subdivided down into 23 specific influencing fac- 
tors (Li et al., 2021b). To avoid repetition, the specific influencing factors can be found in 3.3. We collected data through surveys and interviews. Through the investigation of the Headworks Sub-division of the South-North Water Diversion Project and the South-North Water Diversion Office of Henan Province and the discussion with experts, scholars, and leaders, the direct influence matrix of 23 we obtained influencing factors through the scores of the experts. According to Step (5), we obtained the comprehensive influence matrix, and we can take further steps (6) to get the matrix of the overall effect, in the formula is the identity matrix. According to the causality diagram of the influencing factors of the sustainable supply chain implementing the water diversion project and the operating rules of the code, and the threshold value is set to be $0.05,0.12$, and 0.14 respectively for comparison, (too large or too small threshold value will make the matrix become " 0 or 1 " matrix), through the value in the $0.05-0.27$ time and again experiment, the division results have logical errors or do not meet the actual situation discarded, and finally came to the conclusion that when the threshold value of $0.05,0.12,0.14$ respectively is more reasonable and the relationship between the factors are simplified. $0.12,0.14$ are more reasonable and the relationship between the factors is simplified, continue to combine expert opinions through interviews and other means, and finally take the threshold value of 0.12 . The reachable matrix is further obtained through Step (7). According to Step (8) and Step (9), Matlab software is used to divide the reachable matrix to obtain the skeleton matrix of the sustainable supply chain for the water diversion project (Table 1).

\subsection{Construction of Multilevel Hierarchical Structure Model}

According to the results of the partition of the skeleton matrix, the influencing factors of the sustainable supply chain implementing the water diversion project are divided into five levels (Figure 2).

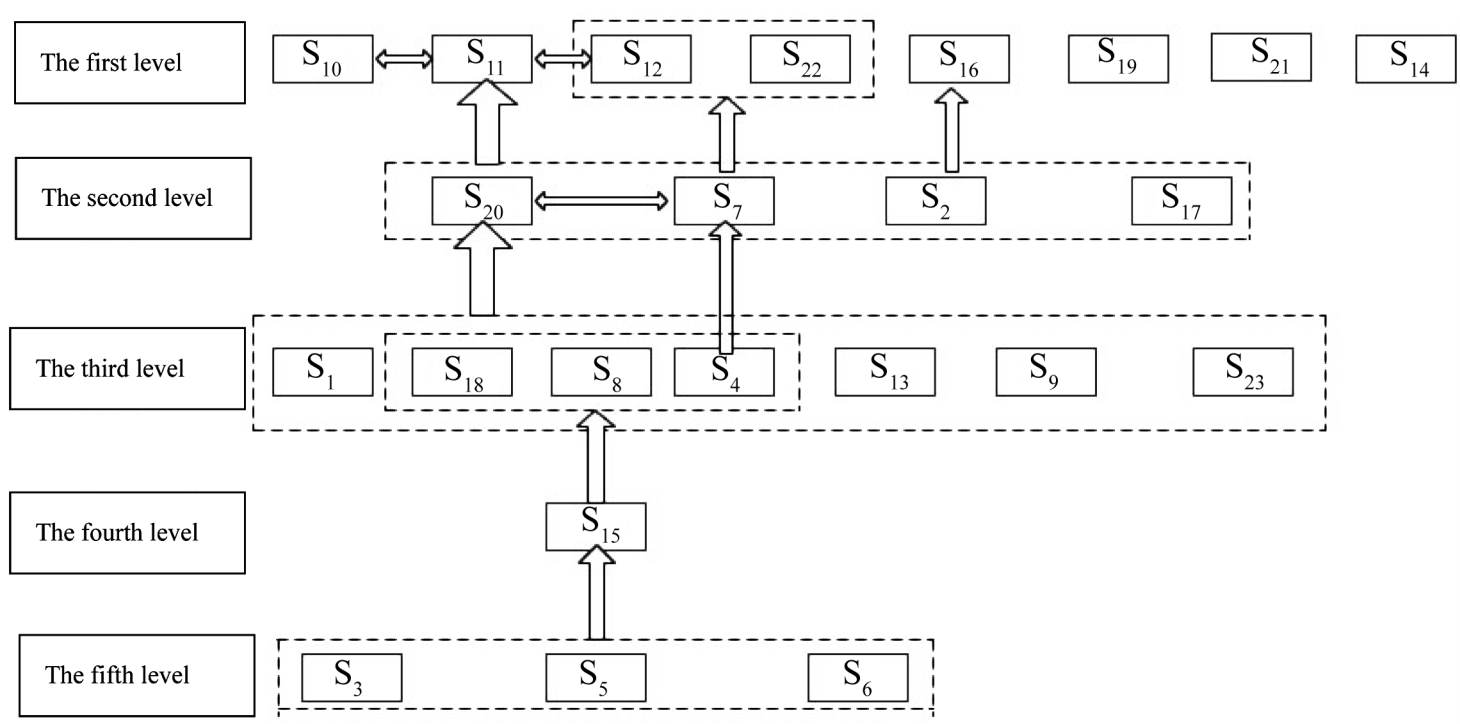

Figure 2. Sketch of multi-level recursive structure model with 23 influencing factors (see 3.3 for details). 
Table 1. A skeleton matrix of sustainable supply chains for implementing water diversion projects.

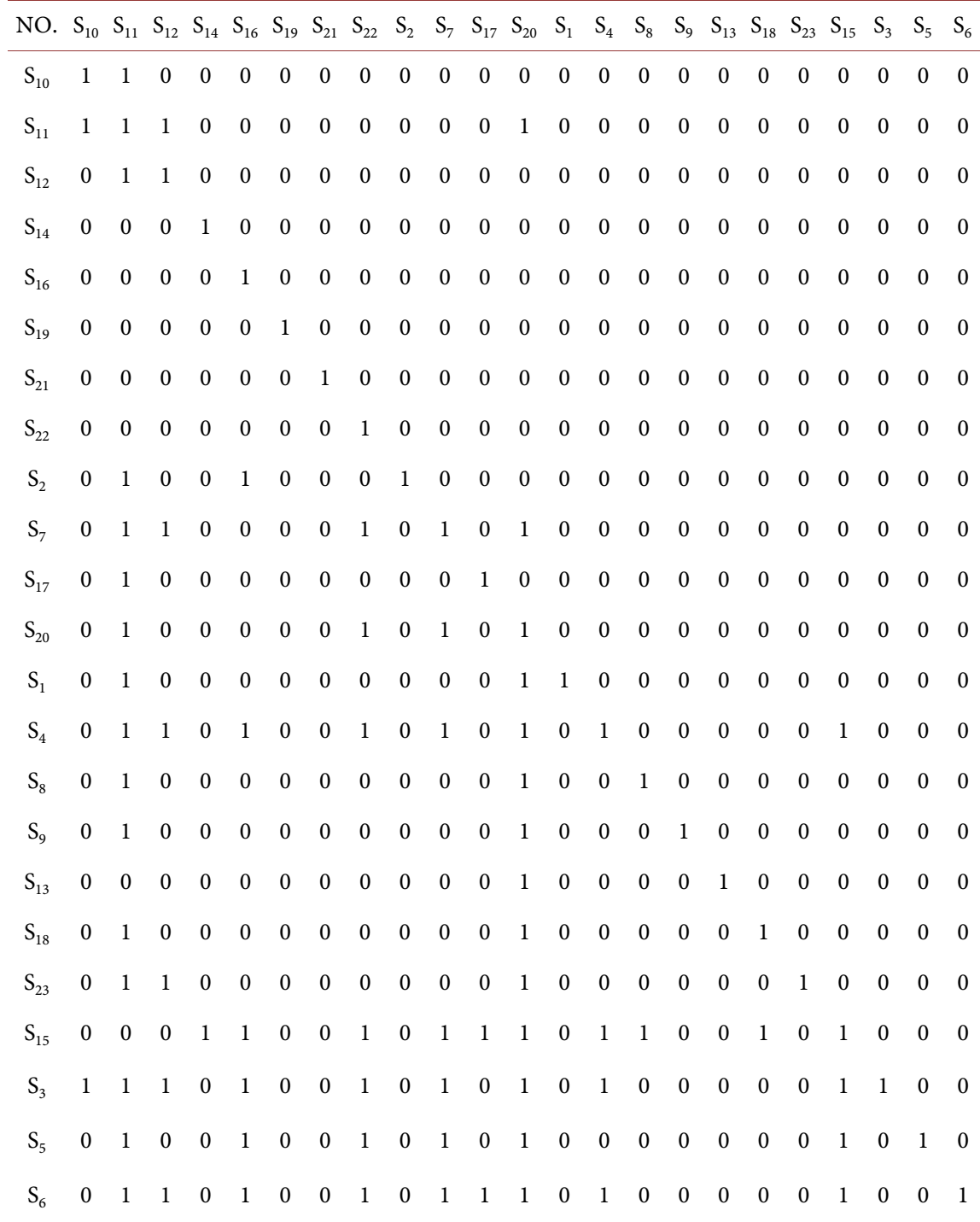

\subsection{Analysis Results of ISM Model}

All influencing factors can be divided into five levels according to the sustainable supply chain's obtained multilevel hierarchical structure model affecting the water diversion project (Figure 2), consists of Water-saving awareness, water-saving intensity (S10), water quality (S11), water pollution disasters (S12), effective incentive mechanism, financial transfer, the closeness between members of the nodes of the supply chain (S19), training and education (S21), and the water animal or plant that has invaded the ecological balance (S14). These direct factors affect the sustainable supply chain for implementing water diversion projects; water-saving intensity and effective incentive mechanism will directly determine whether the water transfer project can implement a sustainable supply chain. Furthermore, the water-saving awareness, water-saving intensity (S10), water quality (S11), and water pollution disaster (S12) in the transfer area 
are highly interactive, and their influences on the sustainable supply chain implementing the water transfer project are usually consistent, which can be considered as an independent system. Changing one of these factors will have less impact on a sustainable supply chain for implementing the water diversion project, so the relationship between the three needs to be well coordinated.

The second level contains Supply chain water quality and water quantity guarantee rate (S20), government's executable power for laws and regulations (S7), water price customization (S2), industry's Green Development (S17), in which the guaranteed rate of water quality and quantity of supply chain (S20) and the government's executable power of laws and regulations (S7) are highly interactive. The government has strengthened law enforcement efforts to ensure the water quality and quantity of the supply chain and has played a driving role in combining the two. Supply chain water quality and water quantity guarantee rate (S20), government's executable power for laws and regulations (S7), water price customization (S2), and industry's green development(S17) will all promote the development of water quality at the next level. The government's executable power for laws and regulations (S7) will contain the occurrence of water pollution disasters (S12) and will promote the formation of an effective incentive mechanism (S22); customization of water prices (S2) would also better facilitate financial transfer (S16).

The third level contains: Water allocation (S1), the level of knowledge and technology required to implement a sustainable supply chain (S18), the effective establishment of contracts for water supply at each node of the supply chain (S8), compensation mechanisms for residents of water sources (S4), drought and flood in natural disasters (S13), diversified property rights (S9), and technological breakthroughs in water diversion projects (S23), These factors will promote the realization of water quality and water quantity assurance rate (S20) in the supply chain; the compensation mechanism for residents of water source area (S4) will also promote the government's enforcement of laws and regulations (S7).

The fourth level includes ecological compensation (S15), which will promote the level of knowledge and technology to implement a sustainable supply chain (S18), the effective establishment of the contract of water supply at each node of the supply chain (S8), and the compensation mechanism for the residents of the water source (S4).

The fifth level includes immigration policy (S3), government financial support (S5), and sound laws and regulations (S6). The factors in this level will promote the development of ecological compensation (S15), and as the last profound factor in the ISM hierarchy model, affect the implementation of the sustainable supply chain of the water diversion project.

Through the analysis of ISM results, the 23 influencing factors can be divided into five levels. The first level is the surface influencing aspect, the second, third, and fourth levels are the indirect influencing factors, and the fifth level is the profound influencing factor. Sound laws and regulations (S6), immigration poli- 
cies (S3), and government financial support (S5) will affect the aspects at the third, second, and first levels through the factors that affect the ecological compensation at the fourth level (S15), and each of the two levels will affect the operation of the whole system through such a progressive relationship. If we want to implement a sustainable supply chain in water diversion projects successfully, it will involve enterprises and involve the coordination and cooperation between governments at all levels, upstream and downstream. The construction of water diversion projects will solve the shortage of water resources and the uneven distribution of water resources-water resources and a meaningful way to balance supply and demand. At present, the construction of water diversion projects has been widely accepted and applied globally and has become an essential means for the government to promote economic development and adjust the economic structure. Therefore, implementation of water diversion project of the sustainable supply chain is not only influenced by the development of industry, more affected by the government and the social environment, the implementation of water diversion project of the sustainable supply chain, but we also need to make much effort, only the government, the joint efforts of enterprises and residents, allowing water diversion project of the supply chain to standardization, Finally, we can successfully promote the sustainable supply chain implementation of the water diversion project.

\section{Conclusion}

Based on the results of ISM, the following suggestions are proposed for the implementation of the sustainable supply chain in water diversion projects:

1) From the government's point of view, the relevant regulatory policies and regulations will directly affect the development direction of the relevant industries. For example, because of the high environmental quality requirements of the water transfer project, the development of local heavy industries and other industries must be restricted, which to a certain extent inhibits the development of the local economy. Therefore, the government should make financial compensation for the reduced welfare of the residents of the water supply area. At the same time, the government should also have a strong regulatory role in water allocation, water price customization, and financial support, which all have a particular influence on the implementation of the supply chain.

2) Due to the inherent characteristics of water resources, water pollution and eutrophication of reservoirs may occur during the construction of water transfer projects. Therefore, we should strengthen environmental protection.

3) The water diversion project of the relevant industry should learn the related knowledge and technology of sustainable supply chain, select the outstanding management talent in the process of water diversion project construction, to continue to adhere to the concept of sustainable development, from the structure of the source to reduce the damage to the environment, in the process of understanding the sustainable long-term implementation of the supply chain can bring benefits to society. 
4) All enterprises in the supply chain should strengthen information sharing and always coordinate and cooperate to improve the implementation effect of the sustainable supply chain.

\section{Fund Project}

This research was supported by the Natural Science Foundation of China (Project No. 71974056).

This research was supported by Humanities and Social Sciences Research Project of the Ministry of Education (Project No. 16YJC630081).

This research was supported by Henan Province Higher Education Key Research Project Plan (Project No. 15A110028).

\section{Conflicts of Interest}

The authors declare no conflicts of interest regarding the publication of this paper.

\section{References}

Chen, Z. S., \& Wang, H. M. (2012a). Asymmetric Nash Bargaining Model for the Eastern Route of South-to-North Water Diversion Supply Chain Cooperative Operations. Journal of the Chinese Institute of Industrial Engineers, 29, 365-374. https://doi.org/10.1080/10170669.2012.710878

Chen, Z. S., \& Wang, H. M. (2012b). Optimization and Coordination of South-to-North Water Di Version Supply Chain with Strategic Customer Behavior. Water Science and Engineering, 5, 464-477.

Chen, Z. S. (2013). Coordination Mechanisms for South-to-North Water Diversion: Economic Benefit and Social Responsibility. Resources Science, 35, 1245-1253.

Elkington, J. (1998). Partnershipsfrom Cannibals with Forks: The Triple Bottom Line of 21st Century Business. Environmental Quality Management, 1, 37-51. https://doi.org/10.1002/tqem.3310080106

Gao, Y., Yao, J. W., Chen, G. F., \& Chen, W. Y. (2018). Current Situation and Prospects of Water Diversion Schemes in China. China Water Resources, 4, 49-51.

Guo, Y., \& Tai, X. J. (2018). Game Analysisof Stakeholders in Ecological Resettlement Compensation. Future and Development, 8, 72-76.

Li, Z. G., Liu, M., \& Lu, Y. L. (2021a). Study of Cause and Mode of Sustainable Supply Chain Collaborative Management of Water Transfer Project. Science and Technology Management Research, 41, 170-178.

Li, Z. G., Yang, L. W., Lu, Y. L., \& Zhang, M. M. (2021b). Analysis of Influencing Factors of the Implementation of Sustainable Supply Chain of Water Diversion Project. Yellow River, 43, 75-79.

Lou, J. R., \& Liu, S. (2018). Game Analysis of Supply Chain Profits of Inter-Bain Water Diversion Project. Soft Science, 32, 49-54.

Wang, H. M., Zhang, L. L., Wang, Z. Z., \& Hu, Z. Y. (2004). A Summary of the Feasible Study on Water Resources Allocation in East Line of the Project of Water Transferring from South to North. Journal of Economics of Water Resources, 3, 2-4.

Wang, M. N. (2002). Influence of Trans-Vally Moving Water on Ecological Environment and Its Countermeasures. Environmental Protection, 3, 32-35. 
Yang, P. G., \& Wang, B. F. (2017). An Analysis on the Welfare Loss of Residents in Water Source Area of the South-to-North Water Transfer Middle Route Project. East China Economic Management, 31, 60-65.

Yang, S., \& Li, J. L. (2018). Comprehensive Safety Capability Structure Model of Civil Aviation Pilots Based on DEMATEL-ISM Method. Safety and Environmental Engineering, 25, 108-114.

Zhang, C. T., Ye, Y., \& Wang, Z. (2019). Review and Prospect of Sustainable Supply Chain Management. Statistics and Management, 1, 60-63.

Zhu, L., Chen, J. Y., \& Yuan, J. F. (2020). Research on Critical Factors Influencing the Resilience of Prefabricated Building Supply Chain Based on ISM. Journal of Civil Engineering and Management, 37, 108-114. 